OPTIONS FOR A GLOBAL PANDEMIC TREATY

\title{
The world must act now to be prepared for future health emergencies
}

\author{
An upcoming special session of the World Health Assembly, taking place from 29 November to 1 \\ December 2021, will discuss the benefits of developing a new global agreement on pandemic \\ preparedness and response. It offers a historic opportunity to protect current and future generations \\ from health crises.
}

Covid-19 has affected each and every one of us. This is what sets it apart from other recent crises: no region or country has been spared. In less than two years, we have lost over five million lives to this virus, based only on official counts. It has infected more than 240 million people, so many of whom have been hospitalised in difficult circumstances. Long covid will trouble us for many years ahead. Our collective and individual mental health have been shaken. Children have missed out on education and socialisation, affecting their futures. Economies have suffered losses of trillions and dire effects on employment.

No one wants to see this happen again. Undeniably, individual countries and the global community were insufficiently prepared for this pandemic. Despite laudable ad hoc-initiatives, such as ACT-A and COVAX, the global community has so far failed to ensure equitable distribution of medical countermeasures.

At the same time, experts agree that this will likely not be the last pandemic. We live in the "Age of pandemics," in which pathogens of zoonotic origin, and the challenges posed by anti-microbial resistance, present a continued and growing risk.

While strengthening our prevention capacities, we must also build a system that will ensure a rapid, joint, effective, and equitable global response to future health crises that reaches every corner of the world.

We must learn the lessons from this crisis and make the necessary changes, both in terms of global collaboration to prevent a repeat of this pandemic and strengthening the global system to react better and faster.

This is why, in March this year, 25 heads of state and government issued a bold call for a new global agreement to use the pandemic as a watershed moment to prevent a global crisis of this kind occurring again. Piecemeal reforms and adjustments of the current system will not do the trick. We need fundamental reform.

A legally binding treaty, convention, or agreement, under the auspices of the World Health Organisation (WHO) has the potential to provide the world with an ambitious framework to better prevent, prepare for, and respond to future pandemics and epidemics. We see several benefits.
A new international instrument should break the cycle of "panic and neglect" and elevate high-level political attention for pandemic preparedness and response. Pandemic preparedness and response requires sustained political commitment and investment, even, or just, when a crisis subsides. A new treaty should systematically convene signatories, driving and supporting stronger compliance through a regular review process, and ensuring that pandemic preparedness and response remain a regular feature on world leaders' agendas.

Promoting cross-sectoral cooperation and coherence would be another benefit. The current crisis has shown that preventing, preparing for, and responding to pandemics is beyond the sole remit of health ministries; cooperation across sectors is required. Home affairs, civil protection, the environment, trade, transport, and finance policies are equally affected and equally important. What is missing in multilateral cooperation is a single forum that brings together all relevant organizations and actors under one umbrella. A treaty could provide this, closely involving other international organizations with a mandate linked to health threats.

In the past months we have witnessed an impressive, collective reflection process regarding the potential benefits and possible contents of a pandemic treaty. The indispensable substantive pillars of such a treaty are already emerging.

First, during the current pandemic we have seen a multitude of initiatives to address the pandemic and to do better in the future. While not denying their value, a treaty under the auspices of WHO would build coherence and avoid fragmentation. Currently, it is the only substantial proposal that would create a global, inclusive forum to discuss and improve pandemic preparedness and response.

Second, we need equitable access to safe and effective medical countermeasures, such as vaccines, therapeutics, and diagnostics. While some countries have enjoyed privileged access to high-quality medical countermeasures, others have faced extreme shortages. We must increase and globalise production, strengthen supply chains and regulatory systems, and put in place long term mechanisms to improve equitable access. This could include a framework for concrete measures to develop, manufacture, and scale up new countermeasures, 
and improve equitable access to existing countermeasures.

Third, we need to share data, samples, technologies, and benefits. In view of the cross-border nature of communicable diseases, it is necessary that all relevant knowledge is available worldwide as soon as possible. A new instrument could potentially include a multilateral framework for sharing surveillance and monitoring data, genetic data and pathogens. It could also include mechanisms to facilitate research and rapid sharing of technology and new insights.

Fourth, we must recognise the importance of One Health. Our health is a continuum across human, animal, plant, and planetary health. To reduce the risk of zoonotic diseases in the future, the human, anima and environmental health sectors must cooperate more closely. A new instrument could strengthen existing platforms and surveillance, further multisectoral partnerships, and promote specific countermeasures in line with the One Health approach, built on robust health systems at national level.

From 29 November, the World Health Assembly will convene in a Special Session to consider the benefits of a pandemic treaty or other international instrument with a view to establishing an intergovernmental negotiation process.

The momentum is there. More than 70 WHO Member States are already in favour of a treaty, and we are observing growing support to start negotiations, alongside the proposal to strengthen the existing International Health Regulations as well as WHO’s important technical work.

We need to save lives and prevent a repeat of covid-19, and the only way to do that is through collaboration, investing in national and global systems to prevent and respond to outbreaks, and equipping and empowering WHO, once and for all, to fulfill its role as the pivotal player in global public health.

We urge all WHO Member States to support the opening of negotiations towards a new instrument at the upcoming World Health Assembly. We must seize this historic opportunity to get global preparedness and response in order. We cannot wait for the next crisis before we act.

Ogerta Manastirliu, Minister of Health and Social Protection of Albania; Wolfgang Mückstein, Minister of Health, Austria; Frank Vandenbroucke, Deputy Prime Minister and Minister of Social Affairs and Public Health, Belgium; Enrique Paris M, Minister of Health, Chile; Daniel Salas Peraza, Minister of Health, Costa Rica; Vili Beros, Minister of Health, Croatia; Magnus Heunicke, Minister of Health, Denmark; Tanel Kiik, Minister of Health and Labour, Estonia; Jens Spahn, Minister of Health, Germany; Athanasios Plevris, Minister of Health, Greece; Stephen Donnelly, Minister of Health, Ireland; Roberto Speranza, Minister of Health, Italy; Mutahi Kagwe, EGH, Cabinet Secretary for Health, Kenya; Lenert Paulette, Minister of Health, Luxembourg; Chris Fearne, Deputy Prime Minister and Minister for Health, Malta; Ala Nemerenco, Minister of Health, Moldova; Jelena Borovinic-Bojovic, Minister of Health, Montenegro; Hugo de Jonge, Minister of Health, Welfare and Sport, the Netherlands; Ingvild Kjerkol, Minister of Health and Care Services, Norway; Kwon Deok-Chul, Minister of the Health and Welfare Ministry, Republic of Korea; Cseke Atilla, acting Minister of Health, Romania; Ngamije M. Daniel, Minister of Health, Rwanda; Lena Hallengren, Minister for Health and Social Affairs, Sweden; Vladimir Lengvarsky, Minister of Health,

Slovakia; Janez Poklukar, Minister of Health, Slovenia; Carolina Darias, Minister for Health, Spain; Anutin Charnvirakul, Deputy Prime Minister and Minister of Public Health, Thailand; Ali Mrabet, Ministry of Health, Tunisia; Fahrettin Koca, Minister of Health, Turkey; Sajid Javid, Secretary of State for Health and Social Care, United Kingdom; Viktor Liashko, Minister of Health, Ukraine; Stella Kyriakides, EU

Commissioner for Health and Food Safety.

Competing interests: none declared.

Provenance and peer review: commissioned, not peer reviewed.

This article is part of a collection of articles on a global pandemic treaty. The collection was proposed by the Global Health Centre at the Graduate Institute. The BM/edited and made the decisions to publish the articles. Article handling and open access fees are funded by a research project at the Global Health Centre, Graduate Institute, Geneva. Kamran Abbasi and Juliet Dobson are the editors for The BMJ. 